\title{
REPRESENTAÇÕES DE GÊNERO E ETNIA EM DESIGN DE EMBALAGENS: PRODUTOS COSMÉTICOS DIRECIONADOS A MULHERES NEGRAS.
}

\author{
GENDER AND ETHNIC REPRESENTATIONS IN PACKAGING DESIGN: \\ COSMETIC PRODUCTS FOCUSED ON BLACK WOMEN.
}

Elisa Conceição da Silva Rosa'

Maristela Mitsuko Ono ${ }^{2}$

\begin{abstract}
Resumo:
O principal objetivo deste artigo é trazer uma contribuição aos estudos e pesquisas sobre gênero, etnia e design. As considerações aqui apresentadas fundamentam-se na perspectiva de gênero e etnia como construções culturais e sociais de identidades ou identificações. Entende-se que o design de artefatos é portador de significados que vão além das funções práticas e técnicas, abarcando também fatores subjetivos, simbólicos, dentro da complexidade, pluralidade e variabilidade de contextos sociais, culturais, ambientais, econômicos e políticos, dentre outros, em que se inserem os individuos e grupos sociais. Sob este prisma, este trabalho discute a questão de representações de gênero e etnia no design de mídias gráficas, com base em um estudo de caso sobre design de embalagens de produtos cosméticos direcionados a "mulheres negras". A metodologia adotada segue uma abordagem interpretativa (GEERTZ, 1989; MOREIRA, 1995), com pesquisa de cunho qualitativo. Os procedimentos metodológicos adotados compreendem entrevistas semi-estruturadas e pesquisa iconográfica.
\end{abstract}

Palavras-chave: Design de embalagens. Etnia. Gênero.

\begin{abstract}
:
The principal aim of this paper is to bring a contribution to the studies and research on gender, ethnic groups and design. The considerations here presented are based on the perspective of gender and ethnic groups as cultural and social constructions of identities and identifications. It is here understood that the design of artifacts carries meanings, which go beyond the practical and technical functions, also enclosing subjective, symbolic factors, within the complexity, plurality and variability of social, cultural, environmental, economic and politic contexts, amongst others, in which the individuals and social groups are inserted in. This paper discusses about the issue of representations of gender and ethnic groups in the design of graphic media, based on a case study about packaging design of cosmetic products that are focused on "black women". The methodology adopted follows an interpretive approach (GEERTZ, 1989; MOREIRA, 1995) with a qualitative research, and the methodological proceedings enclose semi-structured interviews, as well as iconographic research.
\end{abstract}

Keywords: Ethnic groups. Gender. Packaging design. 
Introdução:

Por meio das embalagens, a indústria busca estabelecer relações com o consumidor, referentes aos atributos do produto e valores subjetivos relacionados à representação e busca de identificação que promovam o consumo. Neste contexto, a indústria cosmética apresenta-se como um mercado em evidente expansão.

No que tange à questão de gênero, poder-se-ia ampliar o prisma de discussões acerca de estratégias e práticas, envolvendo representações de gênero em projetos de produtos para a sociedade, que poderiam estar promovendo a reprodução e a produção desigualdades e discriminações na sociedade.

Novos produtos surgem no mercado, prometendo uma participação importante no dia-a-dia da mulher, para que nela se retratem cada vez mais atributos de beleza e satisfação. O design de tais produtos buscaria um modelo de representação da consumidora que a levaria a tentar reproduzir em si características imagéticas criadas como referências estéticas na sociedade.

Hoje, no Brasil, a indústria cosmética é liderada por empresas multinacionais que trabalham em diversas linhas de produtos e variações de extensões de linha específicas. Em tal contexto, observam-se certas tendências em direcionar determinados cosméticos a segmentos especificos de mulheres, de acordo, por exemplo, com o tipo de pele, cabelo e mesmo odores relacionados a certas identificações étnicas, como demonstra o estudo caso apresentado neste trabalho.

\section{Cultura e identidade}

Para um melhor esclarecimento sobre a abordagem teórica contemplada neste artigo, que trazem as temáticas de gênero e etnia como construções culturais e sociais, envolvidas no design gráfico de embalagens, abre-se uma breve reflexão sobre cultura e identidade.

A cultura é vista aqui não como um acontecimento que emerge a partir de uma natureza humana previamente determinada, mas, de acordo com o pensamento de Geertz (1989, p.74), em relação aos sujeitos que são modificados por "costumes e lugares particulares". Desta forma, considera-se que os significados construidos pelo próprio ser humano, em relação ao lugar que ele vive e sua interação com o que o cerca, o faz constituir a cultura que orienta seus pensamentos, seus valores, seus comportamentos, dentro da complexidade e dinâmica das transformações sociais.

Sob este prisma, as pessoas não estariam condicionadas a agir de um mesmo modo, oriundo de uma natureza humana vista fora dos acontecimentos diversos que emergem para além de considerações genéricas sobre os sujeitos. Ao contrário, é necessário considerar lugares e costumes particulares conforme Geertz (1989) - ao se refletir sobre a relação do sujeito construindo significados dentro de contextos diversos. 
Como afirma Hall,

A identidade torna-se uma 'celebração móvel': formada e transformada continuamente em relação às formas pelas quais somos representados ou interpelados nos sistemas culturais que nos rodeiam. [...] A medida que os sistemas de significação e representação cultural se multiplicam, somos confrontados por uma multiplicidade desconcentrante e cambiante de identidades possiveis, com cada uma das quais poderíamos nos identificar - ao menos temporariamente. (2005, p. 13)

A questão da identidade remete a identificar-se com algo ou alguém. Visto a quantidade de possibilidades de identificação, poder-se-ia dizer que há vários sistemas de Teferência que cooperam na construção da identidade. Assim, a identidade pode ser vista como um processo, ou seja, que acontece à medida que ocorre a identificação.

No contexto do processo de globalização, apontado por Hall como um dos fatores que impactam nas identidades culturais, "as sociedades modernas são [...], por definição, sociedades de mudança constante, rápida e permanente". (HALL, 2005, p.14).

Tal processo acentuou-se, no Brasil, notadamente a partir da década de 1990, com a política de abertura comercial do país, trazendo significativas influências culturais, sociais e econômicas, dentre outras. Em tal contexto, proliferaram-se empresas multinacionais, muitas das quais têm se destacado como líderes de mercado, como é o caso da empresa de cosméticos Unilever, focalizada no estudo de caso tratado no presente artigo.

Com a quantidade cada vez mais freqüente e acessível de produtos diversos, salienta-se a importância das empresas buscarem compreender cada vez melhor a pluralidade, diversidade e variabilidade de identidades das pessoas, a fim de nelas promoverem identificações que estimulem o consumo de seus produtos.

Ao observar-se uma prateleira de farmácia, por exemplo, percebe-se a crescente segmentação de produtos, a variedade dentro de uma mesma linha, que visam a atender diversos clusters de identificação.

Dentre as construções culturais e sociais de identificações, figuram as de gênero e etnia, focalizadas no presente trabalho e discutidas a seguir.

\section{Gênero e Etnia}

Entende-se aqui que os conceitos de gênero emergem das relações sociais e culturais, e, simultaneamente, influenciam o desenvolvimento das mesmas. O termo gênero "é uma categoria social imposta sobre o corpo sexuado", ou seja, desde que se entende que socialmente foram constituidos parâmetros que distinguem áreas, atribuições, comportamentos, para homens e mulheres - papéis sociais- o termo torna-se uma forma de indicar construções culturais. (SCOTT, 1995, p.75).

Considerando-se que a noção de gênero é culturalmente construída, entende-se que não se pode fundamentá-la, reduzindo-o a diferenças biológicas que determinam o sexo de um indivíduo. "se gênero são os significados culturalmente assumidos pelo corpo sexuado, não se pode dizer que ele decorra 
de um sexo [...] a distinção sexo/gênero sugere uma descontinuidade radical entre corpos sexuados e gêneros culturalmente construidos." (BUTLER, 2003, p. 24).

Há de se observar que houve fatos históricos em que os sujeitos eram hierarquizados por meio de evidências biológicas, apenas como: "cor de pele, sexo anatômico, formato do crânio [...] ainda hoje estamos sujeitos a alguns desses valores, enquanto outros se perderam." (LOURO et al, 1995, p.187)

Desta forma, são reproduzidos determinados valores, amparados em fatores biológicos, alguns dos quais distinguem seres humanos com base em sexo e raça, por exemplo.

Neste trabalho, considera-se a possibilidade de haver a (re)afirmação de certas diferenças entre os seres humanos, por meio de determinadas representações do corpo, associadas a produtos específicos que tem sido inseridos no mercado e que buscam marcar uma identidade, não somente com base em supostas diferenças biológicas, mas também em categorias representativas de construções sociais e culturais. É o caso, por exemplo, da comunicação visual de grande parte dos produtos cosméticos, que tem veiculado certos padrões estéticos do corpo e propagado a idéia da possibilidade de obtenção de certas configurações corporais, por meio de produtos específicos que funcionariam para marcar uma determinada identidade.

Cabe lembrar, conforme o antropólogo Munanga, o conceito de raça ${ }^{3}$ tem um conteúdo morfo-biológico, e o da etnia sócio-cultural, histórico e psicológico. Para ele, "uma etnia é um conjunto de indivíduos que, histórica ou mitologicamente, têm um ancestral comum; têm uma língua em comum, uma mesma religião ou cosmovisão; uma mesma cultura e moram geograficamente num mesmo território" (MUNANGA, 2003, p.14).

Ono (2006, p. 89) observa que "mesmo em um único pais, como no caso do Brasil, não há, entre as diferentes regiões as realidades sociais e culturais, uma homogeneidade. Ao contrário, a cultura é plural, heterogênea e dinâmica." Segundo a realidade etnográfica do Brasil, não se pode dizer que exista uma única cultura branca e uma cultura negra. O território nacional e a diversidade das populações regionais, segundo Munanga (2003, p.14), nos mostram que "podemos distinguir diversas culturas no Brasil", e, em tal contexto, também as identidades, enquanto processo e não produtos acabados.

Do mesmo modo, gênero e etnia precisam ser tratados com base na perspectiva da diversidade cultural e da pluralidade e variabilidade de identidades e identificações.

A partir dessa ótica, discutem-se, a seguir, representações de gênero e etnia no design de embalagens cosméticas, com enfoque em desodorantes e hidratantes, cujo público-alvo tem sido segmentado por diferenças corporais de cor de pele.

\section{Design Gráfico de Embalagens Cosméticas}

O design gráfico da embalagem oportuniza a identificação das pessoas com certas referências culturais e sociais presentes no cotidiano. 
Quando se opta por um ou outro objeto de consumo, por vezes não se percebe claramente a intenção de identificação e representação com o consumidor, bem como as influências engendradas na construção de valores, referências culturais e nos modos de vida das pessoas.

Os artefatos desenvolvidos para a sociedade, bem como meios de comunicação de massa, tais como a publicidade e propaganda, por exemplo, atingem um número relativamente grande de pessoas, influenciando a criação, a transformação e a reprodução de valores, padrōes de comportamento e práticas na sociedade. (ONO, 2005, p. 27).

No caso de embalagens pertencentes a corporações multinacionais, ocorre, quando da percepção de um grupo de consumidores ativos economicamente, a busca de adequação do design de artefatos a um determinado perfil de público-alvo, variando o grau de consideração e respeito à diversidade cultural no seu desenvolvimento.

No contexto da globalização, esta questão torna-se crucial, levando-se em conta as influências das estratégias adotadas pelas empresas no desenvolvimento de artefatos para a sociedade. De acordo com Lévi-Strauss (apud ONO, 2006, p. 99), “o processo de globalização reflete a natureza essencialmente paradoxal do ser humano e da sociedade, que desenvolvem forças contraditórias: umas tendendo à divergência e à particularização, e outras è convergência e à afinidade", o que se reflete também no desenvolvimento de artefatos, "podendo-se observar a coexistência de produtos globais, locais, particularizados e híbridos" (ONO, 2006, p. 99).

O design gráfico, cercado de significados subjetivos, pretende ser compreendido por e atender objetivamente determinado grupo de pessoas. Desta forma, trabalha com relações de identificação e representação de valores. Para Denis, "o design constitui, grosso modo, a fonte mais importante da maior parte da cultural material ${ }^{4}$ de uma sociedade que, mais do que qualquer outra sociedade que já existiu, pauta a sua identidade cultural na abundância material que tem conseguido gerar." (1998, p.22). E, segundo o mesmo, "os processos de design incidem sobre os seus produtos, investindo-os de significados alheios à sua natureza intrínseca" (DENIS, 1998, p.17).

A embalagem é um veículo de ampla relevância como fonte de apelo para o consumo. Com funções de proteção e informação, ela é, para a maioria das empresas, seu único meio de comunicação.

Como mídia responsável em transmitir ao consumidor as informações necessárias acerca do produto, a embalagem apresenta informações que são regidas e fiscalizadas por órgãos competentes como a Agência Nacional de Vigilância Sanitária - ANVISA $^{5}$, que autoriza tanto o funcionamento de empresas de cosméticos como inspeciona os requisitos técnicos à rotulagem obrigatória. Além dessas, existem informações consideradas importantes do ponto de vista do próprio fabricante e da equipe responsável pela função de comunicação do produto a serem apresentadas por meio da embalagem.

No caso dos produtos cosméticos, identificam-se, dentro de sua variada gama, certas tendências de composição gráfica, com o uso de determinadas cores e formas na representação da "mulher negra", com vistas a fazer com que ela se identifique com o produto.

No caso do Brasil, percebeu-se a possibilidade de ampliação de 
mercado, valendo-se de estratégias de segmentação étnica, sendo que a "mulher negra" passou a compor um "nicho de mercado" local, com um produto diferenciado, desenvolvido especificamente para atender a "necessidade" desta categoria de "mulher", considerada diferente.

Isto pode ser observado no caso do desodorante Rexona e do hidratante Vasenol, da empresa Unilever.

Os produtos da Unilever são comercializados em uma ampla gama de mercados do globo, na maioria das vezes com os mesmos projetos gráficos, cores e mesmos nomes.

Segundo Ono (2006, p. 85) "estratégias voltadas à promoção da imagem corporativa das empresas têm, em muitos casos, levado a um entendimento do design de produtos como algo a ter uma expressão única para vários mercados, com o intuito de fortalecer a associação dos mesmos à marca".

Os desodorantes da linha Rexona (Desodorante Antitranspirante Rollon Rexona Ebony) são considerados a maior marca de desodorantes do mundo e líder de mercado em 29 países. Segundo o site institucional da empresa, "os produtos Rexona trabalham em linhas sob medida para as necessidades de homens e mulheres" (Disponivel em:

http://www.unilever.com.br/ourbrands/personalcare/rexona.asp. Acesso em: 17 jun. 2006, 18:42).

O desodorante Rexona Ebony foi lançado no mercado brasileiro, com investimento de 8 milhões de reais em sua campanha de lançamento, após quatro anos de estudos sobre os hábitos e necessidades dos consumidores, bem como pesquisas qualitativas e quantitativas para testar o mercado. A empresa desenvolveu um produto destinado especificamente para mulheres com pele morena e negra. $\mathrm{O}$ atributo diferencial deste produto defende sua especificidade de público, sobre sua ação de "dupla proteção". A estratégia de promoção do produto, usando este argumento como tema de campanha publicitária, repercutiu com críticas sobre o aspecto de diferenciação entre negros e brancos, e considerou-se que a afirmativa de dupla proteção faz referência a que mulheres negras emitem mais odores que mulheres brancas. Não se pretende aqui discutir as características do produto, mas situar seu lançamento no mercado consumidor brasileiro.

A apresentação gráfica do desodorante Rexona Ebony segue a estrutura dos demais da linha Rexona. Ou seja, na face frontal da embalagem, a tipografia utilizada não se distingue, bem como a disposição e enquadramento das formas. A marca do produto é um sinal de aprovação na forma da letra " $v$ ", com uma elipse aberta em segundo plano. A denotação observada é que a simbologia da marca refere-se à eficácia atestada dos produtos. A marca e o logotipo Rexona são os elementos visuais de maior visibilidade e relevância no projeto gráfico.

Apesar da predominância do branco, a cor que diferencia e caracteriza o produto é a cor de bronze, associado simbolicamente à cor da pele da "mulher negra". Ele é usado na tampa, no rótulo no texto Ebony e nos elementos gráficos de apoio, variando em degradês e contornos para o amarelo dourado.

A linha de hidrantes da marca Vasenol, por sua vez, atua no mercado brasileiro há cerca de 30 anos. A marca é considerada referência na linha cosmética de hidratantes e com nome de marca já conhecido. Segundo a 
empresa fabricante, "Vasenol é considerada especialista no cuidado com a pele, que desenvolve formulações para atender diferenciadas necessidades de hidratação e tratamento." (Disponivel em:

http://www.unilever.com.br/ourbrands/personalcare/vasenol.asp. Acesso em: 17 jun. 2006, 20:17).

Trata-se da primeira marca de hidrantes da Unilever a segmentar o mercado para produtos étnicos. O projeto gráfico não se diferencia dos demais produtos da linha Vasenol na disposição e estrutura gráfica do rótulo. A cor predominante é a de bronze.

A referida cor de bronze remete ao castanho metalizado ou marrom metalizado. Fica evidente a associação do produto ao tom de pele negra e morena, como é descrito no rótulo dos produtos, tanto no caso do Vasenol, quanto do Rexona.

Observa-se, nas'embalagens estudadas, que a cor constitui um fator predominante de diferenciação, em termos de representação de identidade étnica, trazendo à tona a necessidade de uma reflexão sobre os aspectos subjetivos que cercam o uso da cor, a fim de ampliar e aprofundar a análise das embalagens para além dos aspectos meramente comerciais, que envolvem o lançamento e comercialização de certas linhas de produtos.

A predominância de tons castanhos para produtos destinados às pessoas "negras" pode ser observada como elemento diferenciador em pontos de venda. Poder-se-ia dizer que o marrom cerca-se de diversas simbologias, algumas fortemente relacionadas a associações com a natureza (outono, putrefação de material orgânico, entardecer, terra, etc.), bem como com atividades físicas ao ar livre, movimento e força, dentre outras.

Cabe também refletir sobre aspectos subjetivos presentes no design de embalagens, com relação ao fato de a indústria cosmética tem tratado da aparência das pessoas, estimulando, mediante o consumo de produtos, a busca do alcance de certos estereótipos de imagem "ideal" da mulher. Propagam-se, por meio de mensagens visuais, valores subjetivos e a idéia de que, com o uso de determinados produtos, ter-se-ia a oportunidade da pessoa se transformar na referência estabelecida.

Hauge chama de agentes especiais - "visagistas", "fazedores de rosto" - aqueles que tratam de comercializar a aparência física, e, para ele, tais agentes "intermediam" a apresentação do rosto feminino.

A indústria de cosméticos está ávida para oferecer à mulher o maior número possível de preparados [...] oferece serviços que mostram, em sua promessa de valor de uso, uma afinidade funcional macabra com os serviços oferecidos ao capital pelas agências de publicidade. Em ambos os casos, trata-se de uma apresentação publicitária, sendo que cada compradora é uma mercadoria se apresentando e, ao mesmo tempo, comprando assim também a sua comprabilidade. (HAUGE, 1997, p. 108).

O design de embalagens abarca uma função importante dentro da estratégia de promoção do produto, e as embalagens para produtos cosméticos constituem-se instâncias de promoção de representações, de certos padrões estipulados como promessas de adequação a valores socialmente construídos e absorvidos por muitas pessoas como referências absolutas, que, por sua vez, podem gerar sérias crises de identidade e problemas sociais, na medida em que não refletem a complexidade, diversidade e variabilidade da realidade. 
Conforme se observa no estudo de caso sobre o design de embalagens de cosméticos direcionados a "mulheres negras", apresentado neste trabalho, estas, notadamente nos últimos anos, têm sido vistas como consumidoras, e sua representação nas embalagens é visível por meio de determinadas cores e imagens que remetem à diferença em relação a outras etnias.

Vale ressaltar, acerca da questão das representações de gênero e etnia no design de embalagens cosméticas, que “a 'diversidade' não se traduz como 'desigualdade', @ que 'diferença' não significa 'divisão', sendo possível a coexistência harmônica da diversidade na totalidade" (ONO, 2006, p. 97), sendo necessário uma perspectiva não reducionista e determinista da alteridade, e a adoção de abordagens, no design de artefatos, que promovam o desenvolvimento de relações sociais não discriminatórias e excludentes.

\section{Referências}

AGENNCIA NACIONAL DE VIGILÂNCIA SANITÁRIA- ANVISA. Disponível em: <http://www.anvisa.org.br>. Acesso em: 14 de maio de 2006.

BUTLER, Judith. Problemas de Gênero: feminismo e subversão da identidade. Rio de Janeiro: Civilização Brasileira, 2003.

DENIS, Rafael Cerdoso. Design, Cultura Material e o Fetichismo dos Objetos. In: Arcos. Design, Cultura Material e Visualidade. Rio de Janeiro, v. 1, número único, outubro, 1998.

GEERTZ, C. A interpretação das culturas. Rio de Janeiro: Guanabara, 1989.

HALL, Stuart. Identidade cultural na pós-modernidade. 10. ed., Rio de Janeiro: P\&A, 2005.

HAUGE, Wolfgang Fritz. Crítica da Mercadoria. São Paulo: UNESP, 1997.

LOURO, Guacira Lopes. Gênero, História e Educação: construção e desconstrução. Educação e Realidade, Porto Alegre, v. 20, n. 2, p. 101-132, 1995.

MESTRINER, Fábio. Design de Embalagem: curso básico. São Paulo: Makron Books, 2002.

MOREIRA, Herivelto. Pesquisa educacional: reflexões sobre os paradigmas de pesquisa. In: FINGER, Almeri et al. Educação: caminhos e perspectivas. Curitiba: Champagnat, 1995. p. 19-42.

MUNANGA, Kabengele. Uma Abordagem Conceitual das Noções de Raça, Racismo, Identidade e Etnia. In: $3^{\circ}$ SEMINÁRIO NACIONAL RELAÇÕES RACIAIS E EDUCAÇÃO, 2003, PENESB, Rio de Janeiro. Disponivel em: <http://www.acaoeducativa.org.br/downloads /09abordagem.pdf>. Acesso em: 06 jun. 2006, 21:37.

ONO, Maristela Mitsuko ; CARVALHO, Marilia Gomes. Isto é coisa para mulheres: gênero e design no desenvolvimento de produtos para a sociedade. Cadernos de Gênero e Tecnologia, Curitiba, v. 1, n. 02, p. 9-29, 2005.

ONO, Maristela Mitsuko. Design e Cultura: sintonia essencial. Curitiba: Edição da Autora, 2006.

REXONA. Disponivel em: http://www.unilever.com.br/ourbrands/personalcare/rexona.asp. Acesso em: 17 jun. 2006, 18:42.

SCOTT, Joan. Gênero: uma categoria útil de análise histórica. Educação e Realidade, Porto Alegre, v.20, n.2, p.71-94, 1995. 
VASENOL. Disponivel em:

http://www.unilever.com.br/ourbrands/personalcare/vasenol.asp. Acesso em: 17 jun. 2006, 20:17.

Notas:

1 Mestranda do Programa de Pós-graduação em Tecnologia (PPGTE), Universidade Tecnológica Federal do Paraná (UTFPR); Pesquisadora do Grupo de Estudos e Pesquisa sobre Relaçöes de Gênero e Tecnologia - GETEC. Bolsista CAPES. E-mail: ecsrosa@gmail.com .

${ }^{2}$ Doutora em Arquitetura e Urbanismo peal FAU/USP, professora do PPGTE/ UTFPR; Pesquisadora do GeTec; Professora Colaboradora do Programa de Pós-graduação em Design da UFPR. E-mail: maristelaono@gmail.com

${ }^{3} \mathrm{O}$ termo raça tem sido utilizado como conceito para explicar a diversidade humana. Segundo Kabengele Munanga (2003, p.5): "Os patrimônios genéticos são diferentes, mas essas diferenças não são suficientes para classificá-las em raças." "E "a maioria dos pesquisadores brasileiros que atuam na área das relaçōes raciais e interétnicas recorrem com mais freqüência ao conceito de raça. Eles empregam ainda este conceito, não mais para afirmar sua realidade biológica, mas sim para explicar o racismo, na medida em que este fenômeno continua a se basear em crença da existência das raças hierarquizadas, raças fictícias ainda resistentes nas representaçōes mentais do imaginário coletivo de todos os povos e sociedades contemporâneas." (MUNANGA, 2003, p. 12).

${ }^{4} \mathrm{O}$ uso do termo cultura material, que surgiu na década dê 1870, com Edward B. Tylor, apresentava uma visão etnocêntrica e "se referia aos artefatos produzidos pelos 'outros', ou seja, por grupos excluídos da concepção moderna de uma 'civilização ocidental' ${ }^{\prime}$. Para Denis, o conceito de cultural material é usado "no sentido de entender melhor o papel dos artefatos em um mundo em que o consumo de mercadorias e o consumismo constituem-se em fenômenos da maior importância social e cultural." (DENIS, 1998, p. 21).

${ }^{5}$ Agência Nacional de Vigilância Sanitária (ANVISA), vinculada ao Ministério da Saúde, tem como missão: "Proteger e promover a saúde da populaçăo, garantindo a segurança sanitária de produtos e serviços e participando da construção de seu acesso". (Disponivel em: <http://www.anvisa.org.br>. Acesso em: 14 de maio de 2006). 